\title{
E-Management: Configuration, Functions and Role in Improving Performance of Arab Institutions and Organization
}

\author{
Huthaifa Abdelkarim Ali Ellatif \\ Faculty of Computer Sciences and Information \\ Technology, \\ Al-Neelain University, \\ Ph. D in IT,
}

\author{
Sammani Abdulmutalib Ahmed, \\ Professor, Dean Faculty of Scientific Affairs, \\ Al-Neelain University
}

\begin{abstract}
The aim of this paper is to present the concept of Emanagement and evaluate its challenge then trace its implementation in the Arab environment. This paper is interested in throwing the light on the concept of $\mathrm{E}$ management and its mechanism application, where it deals with the concept of management science in terms of importance and theories of management science. so the paper takes the mechanism application of these processes which is called E- management that consists of hardware, software and the networks to achieve limited objectives in advance according to the processes above, then it takes the $\mathrm{E}-$ management system and E- government and its implementation of the most important advantage of Emanagement ,so the most important advantage of that is , the speed of the communication, flexibility and the transparency that keeps up the technology progress, which benefit from access to the resolution and good governance
\end{abstract}

\section{General Terms}

E-management.

E-business.

E-commerce.

Communication network (Hardware /Software).

Arab Environment.

\section{Keywords}

E-management, E-management Infrastructure, E-management Components, E-management Functions and Chances of Success of E-management in Arab Environment

\section{INTRODUCTION}

E-management is an important outcome of IT and communication net mechanisms in the digital world. Emanagement's systems, tools, hardware and software are examples of the new mechanisms on the internet and in the new economy of knowledge. Electronic mechanisms which are less than one decade old are still in the stage of on-going development. Nevertheless, their impact on the configuration and functions of E-management is immense and comprehensive as it has drastically changed both theoretical and practical applications of E-management through the new systems, tools and models of creating wealth and realizing value added in addition to new ways of competition based on innovation.
The term E-management is often used as a synonym to EBusiness, E-Commerce and other similar concepts and activities within the digital world are:

1.1 E-Business is less than a decade old. It was introduced by IBM in 1997 within the context of its intense endeavor to differentiate between electronic mechanisms activities and E-Business activities. IBM identified E-Business as "a comprehensive flexible approach to distribute the value of distinguished works by linking systems to operations through which basic activities of business are conducted".

1.2 E-management is a concept, system, functional configuration and activities that depends in its operation on internet networks to achieve predetermined objectives.

In view of the expansion of the internet and IT systems, three changes emerged in technology patterns during the last few years, these are :

- Quantitative development in IT in terms of volume of data and speed of transmission

- Connectivity and continuity of computerization and communication

- Wide usage of digital information and multi-media which led to the emergency of virtual reality and multi-dimensional information

\section{E-MANAGEMENT COMPONENTS}

Elements of E-management are electronic elements themselves. They consist of hardware, software, communication networks and management concepts and mechanisms of their application.

\section{E-MANAGEMENT FUNCTIONS}

E-management is an organizational and functional system that is flexible and open to exchange and shares its effects with environments that are internal or external to the organization. Therefore, it is possible to set Non-electronic management functions within the modern IT means and techniques as these have immensely affected the context of the management process in its normal form. Hereunder are the changes reflected in the E-management function :

3.1 Movement from independent computerized data system to network systems. IT systems have become an electronic fabric that is neatly connected to 
production, marketing, accounting, financing, HR and research and development centers.

3.2 Movement from Non-electronic management systems to smart E-management systems whereby the latter could deal with information sources that produce smart elements such as databases and software that search for information.

3.3 Movement from gradual processing to instant processing (on-line analytical systems). This is a qualitative revolution compared with the old system. It suits the changing and swift nature of doing business which requires continuous updating.

3.4 Working through networks. E-management in modern organizations works through linking of databases via internet technology designed to provide staff with their needs of internal information. Extranet as opposed to Intranet provides staff and other selected third parties with the information they need.

3.5 Working through Client/Server Computing which is linked through a network. There are some important rules to coordinate interaction between client and server:

- On receipt of request from a client the server must make sure of the authenticity of transfer and legitimacy of the request The server may provide service to multiple users and the user may request service from multiple servers

- Regardless of the type of processor, the server must be reliable and easy to use

3.6 Processors have changed from central structures to flexible environment structures. One of the results of application of E-management technologies is the emergence of a fundamental change in the environments of processors. With the application of Emanagement the processors changed from central functionality to flexible structures and team-work rather than individuality. This has been coupled with the intensive use of modern technologies, networking, creation of strategic units and globalization.

3.7 Movement from the concept of relative advantage to the concept of assured competitive advantage. The former has been prevalent for quite some time and associated with Non-electronic competition in management. The latter emerged based on the competencies of the organization compared to the five competition forces known as (PORTER) and the strategic competition forces in the market.

These important technological changes have contributed to creating a new way of E-management that is quite different from the former way and have changed the context of Nonelectronic management functionality.

\section{E-MANAGEMENT \\ INFRASTRUCTURE}

E-management emerged following the widespread use of computers in the 1950s and 1960s when organizations realized that using computers meant convenience and saving of time, effort and resources. One of the consequences of the development of computers and communications is the emergence of electronic exchange of information and messages between beneficiaries, i.e. application of electronic exchange of information was motivated by the need to develop activities of organizations and to enable them have direct links with their branches through communication networks as a first stage and then linking an organization with other organizations to share information and resources.

it can be safely said that the emergence of electronic data sharing systems and networks represented the cradle for the birth of E-management and the development of its new functions and roles through the use of modern networks, especially intranet and extranet, digital space, internet and technological infrastructure of IT. Therefore, we shall discuss network technology as its indispensable components in Emanagement. We shall refer to:

\section{1 electronic exchange of information:}

Electronic exchange of information is defined as the electronic movement of a package of messages in the presence of agreed criteria from one computer to another without the need for human interference. Accordingly, the main characteristics of electronic exchange of information are:

- Messages exchanged between sender/receiver must be structured

- Messages exchanged must be standardized

- It is possible to exchange messages between sender/receiver regardless of difference between the two organizations and equipment and software used by them (application independent)

- Exchange of information takes place electronically without the need for human interference.

\section{2 internet network:}

It is a global information network comprising huge interlinked packages of information from thousands of networks all over the world. In addition to intranet networks internet comprising millions of host computers linked through communication channels, including cables and fiber optics and other means. Internet is also linked through satellites without which the network could not possibly work with high efficiency.

\subsection{E-management and Internet:}

E-management and E-Business before the emergence of internet were in the process of slow development. However, they made a gigantic step forward with the introduction of internet. This was a historic phenomenon born in the $21^{\mathrm{st}}$ century. E-business, E-banking and E-services were born in internet environment and developed with the development of internet.

Internet has changed the rules of conducting E-Business as it has enabled interested parties to use opportunities available in the electronic information environment to maximize gains. Internet has immense importance in E-management and the development of the new digital economy. Its importance stems from the following:

- Internet is the mother of all other communication networks (LAN intranet, extranet)

- Internet is the means for E-management to build Eeconomy

- Internet is the means for E-management to enter markets and meet clients' requirements

- Internet is the base for selection of options to develop communications technologies and the transformation of economic and social organizations 


\section{CHALLENGES OF E- MANAGEMENT}

It is difficult to draw a comprehensive map for all the digital opportunities accrued as a result of the application of Emanagement as these opportunities are tied to E-Business activities and the job openings from different organizations, including electronic marketing, electronic services, electronic financing, electronic advertisement and many other activities conducted electronically. Digital opportunities may be classified into three categories:

\section{Electronic operations opportunities \\ Electronic marketing opportunities \\ Electronic services opportunities}

Electronic operations opportunities use network technologies (extranet, intranet and internet) to effect strategic change in the management process and in the chain of values of main and support activities being conducted. This includes activities of project planning, information management to maximize efficiency, speed up of information flow and computerization of activities and operations in environments both internal and external to the organization.

Electronic marketing opportunities open windows to global market through the administration of web site to instantly reach clients all over the world quite easily and at minimum cost. This reinforces inclusion of the organization in the EBusiness world and avoiding restrictions of time and place. The opportunities provided by electronic marketing enable the organization to build intimate interactive relations with clients and help meeting their demands.

\section{E-MANAGEMENT AND KNOWLEDGE}

E-Management could be described as a network of knowledge scattered all over the world. The base of the knowledge system stems from E-Management capacity to receive, mobilize, store, update, analyze and disseminate knowledge and conduct activities, take decisions and learning from the process and its results.

The success of E-Management in the creation of a chain of information value to accommodate basic activities; complement this chain by fundamental activities to accumulate knowledge helps in building and developing knowledge management systems and supporting the dynamics of the accumulation of knowledge

An organization could benefit from the strategic support of EManagement and knowledge management in achieving a number of things, including:

- Assurance of quick access to knowledge compared to competitors

- Best sharing knowledge

- Avoiding extra costs

- Maximizing profitability and achieving fast growing revenues

- $\quad$ Shorter time to access markets

- Improving relations with clients

- Opportunities for new business

\section{E-MANAGEMENT CHALLENGES IN ARAB ENVIRONMENT}

May be it is not possible to present an objective comprehensive analysis to the reality of E-Management in Arab environment and other issues of relevance to application of E-Management programs in Arab countries for a number of reasons including, the generality of the topic and its inclusion of various fields such as IT, communications, internet, ecommerce and e-government programs and investment plans in the production of software in some Arab countries.

Limitations on the application of E-Management in Arab environment can be classified into three broad categories that we discuss in the following points:

7.1 Technological Limitations: limitations that impede application of E-Management programs include all issues pertinent to the reality of infrastructure of IT, communications, use of internet and the development of software production and information technology services. At the level of technology development and communications we can say that the Arab world is still lagging in the use of modern technology, including computers, compared to the rest of the world.

7.2 Cultural Limitations: study of the organizational culture of each individual organization. The differences include administrative and ways and traditions of work and the nature of activities performed.

7.3 Organizational Culture: organizational culture refers to set of values and traditions shared by all workers in a clear way in the organization. This culture develops with the growth and development of the organization and reacts to the social, economic and cultural fabric within which it exists. Workers bring to the organization their own values, customs and traditions which in turn affect the organizational culture of their organization. The organization on its part affects the lives of the workers, especially their ways in performing duties and keeping pace with level of performance targeted by the organization.

7.4 Organizational Culture and E-Management: being aware of the organizational culture and the way this culture is maintained helps in the planning and application of systems and tools of E-Management. The organizational culture prevailing in the organization constitutes an important element in the development of E-Management projects. EManagement requires prevalence of innovation culture, i.e. thinking out of the box while taking a deeper look into the reality of the organization. Such thinking should consider all changing factors in the outside environment that affect work of the organization and which require introducing fundamental changes in the organizational culture of the organization.

7.5 Arab Admin Culture and E-Management: the word culture denotes development of brain capacity through training and practice. Arab culture refers to all productions of Arab brains that make up Arab traditions all facets of life. Arab managers, regardless of their nationalities, recall thoughts from the Arab culture. Arab admin culture must be strong enough to provide Arabs with innovative thinking tools to keep pace with modern technologies. Arab culture must also provide all Arabs, especially managers, with 
intellectual capacities that help in the development and application of E-Management systems.

7.6 Socio-economic Limitations: shifting to EManagement is part of the inclusion into information economy world and, is an important step towards building information community. With the emergence of such thoughts and the rising of new forces and functions social formations change to accommodate new technologies. This happens at the level of society and the level of organizations. Because of the socioeconomic context of E-Management computerized systems cannot be developed in vacuum. They need the right socio-economic environment which in turn leads to the success of E-Management.

Within this context we can say that Arab socio-economic environment can produce forces resistant to projects such as E-Management, E-Business and other similar activities. Therefore, it is important E-Management teams should consider collective participation in their projects to ensure changing attitudes of their societies to accommodate and accept E-Management, IT and communications.

If attitude towards E-Management is acceptable, chances of success at the level of organizations and at the level of society at large will be big and clear.

Industrial revolution has led western society into modernity. In today's world the technological revolution is leading the whole world to what may be called "beyond modernity". Western societies have now become "web" societies. Within the same context, technological revolution is stimulating the Arab world to enter into the world of comprehensive and sustainable development. Arab development should avoid western modernity crisis manifested in materialistic gains and suppression of social and cultural values.

This means that efforts to use tools of information technology for socio-economic change must go hand in hand with efforts to rebuild society on strong base to avoid unexpected fundamental changes in social norms. Not only that but without this social dimension contribution of IT, EManagement and communications will be limited and will be rather weak.

Arab industries are still traditional in nature and do not require intensive use of IT and communications. The spread of electronic activities, such as E-Management, E-Commerce and E-Government is slow and limited in Arab countries. On the other hand the development of IT and communications sector in Arab countries will reinforce and strengthen economic growth, improve productivity, create employment opportunities and stimulate social exchange and economic activities. These in turn will positively affect the welfare of individuals and society at large.

If Arab countries succeeded in formulating IT strategies at the levels of E-Management and E-Commerce and managed to develop communications and investments in IT services, they will definitely succeed in invigoration of sustainable development and all these tools will become forces driving all economic sectors.

\section{CHANCES OF SUCCESS OF E- MANAGEMENT IN ARAB ENVIRONMENT}

Regardless of the limitations of application of E-Management in Arab environment, the chances of successful EManagement development strategies are present provided there is serious commitment and well prepared development programs to achieve a balance between the Non-electronic (materialistic) side and the digital side in the Arab economies and government administrations at the national level. What Arab countries need is the formulation and application of ambitious IT strategies in different areas.

To Sum up it could be said that the successful application of electronic activities, including E-Management and ECommerce, is possible. This is evident from live examples in some Arab countries. Requirements of success of EManagement projects in Arab environment are:

- Development of IT development strategy for shifting to information economy.

- Restructuring of basic IT and communications environment

- Restructuring of education strategies to keep pace with opportunities made available by the knowledge economy, including building of cultural strength through innovation.

- Provision of the right legal and legislative environment for E-Management and E-Commerce. Legal and legislative structures in some Arab countries need reconsideration.

- Re-engineering of IT activities in public and private institutions in Arab countries.

- Set plans to bridge the digital gabs between Arab countries.

\section{RESULTS OF QUESTIONNAIRE ON IMPROVING PERFORMANCE THROUGH THE USE OF E- MANAGEMENT}

A questionnaire has been prepared and distributed to different institutions. The questionnaire intended to gauge percentages of using Non-electronic system and the proposed electronic system. Hereunder are the questions and the results. 


\subsection{Non electronic system result}

Table 1. The results of the analysis of the questionnaire Non-electronic system

\begin{tabular}{|c|c|c|c|c|c|c|}
\hline \multirow{2}{*}{ Е. } & options & hrs 2-1 & $\begin{array}{l}5-3 \\
\text { hrs }\end{array}$ & $\begin{array}{l}8-6 \\
\text { hrs }\end{array}$ & $\begin{array}{c}12-10 \\
\text { hrs }\end{array}$ & $\begin{array}{c}\text { More than } \\
12 \mathrm{hrs}\end{array}$ \\
\hline & result & $\% 0$ & $\% 0$ & $\% 16$ & $\% 22$ & $\% 62$ \\
\hline \multirow{2}{*}{$\begin{array}{l}\delta \\
2\end{array}$} & options & $V$ few & few & $\begin{array}{c}\text { averag } \\
\mathrm{e}\end{array}$ & many & Too many \\
\hline & result & $\% 0$ & $\begin{array}{c}21.5 \\
\%\end{array}$ & $\begin{array}{c}70.25 \\
\%\end{array}$ & $\% 8.25$ & $\% 0$ \\
\hline \multirow{2}{*}{ } & options & excellent & good & $\begin{array}{c}\text { averag } \\
\mathrm{e}\end{array}$ & weak & V weak \\
\hline & result & $\% 0$ & $\% 12$ & $\% 56$ & $\% 32$ & $\% 0$ \\
\hline \multirow{2}{*}{ 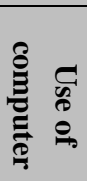 } & options & $\begin{array}{c}\text { Strongly } \\
\text { support }\end{array}$ & $\begin{array}{c}\text { supp } \\
\text { ort }\end{array}$ & $\begin{array}{c}\text { Neutra } \\
1\end{array}$ & $\begin{array}{c}\text { Not } \\
\text { supportin } \\
\mathrm{g}\end{array}$ & $\begin{array}{c}\text { Strongly } \\
\text { not } \\
\text { supporting }\end{array}$ \\
\hline & result & $\% 0$ & $\% 0$ & $\% 0$ & $\% 21$ & $\% 79$ \\
\hline
\end{tabular}

9.1.1 Presentation of Non-electronic system results in charts:

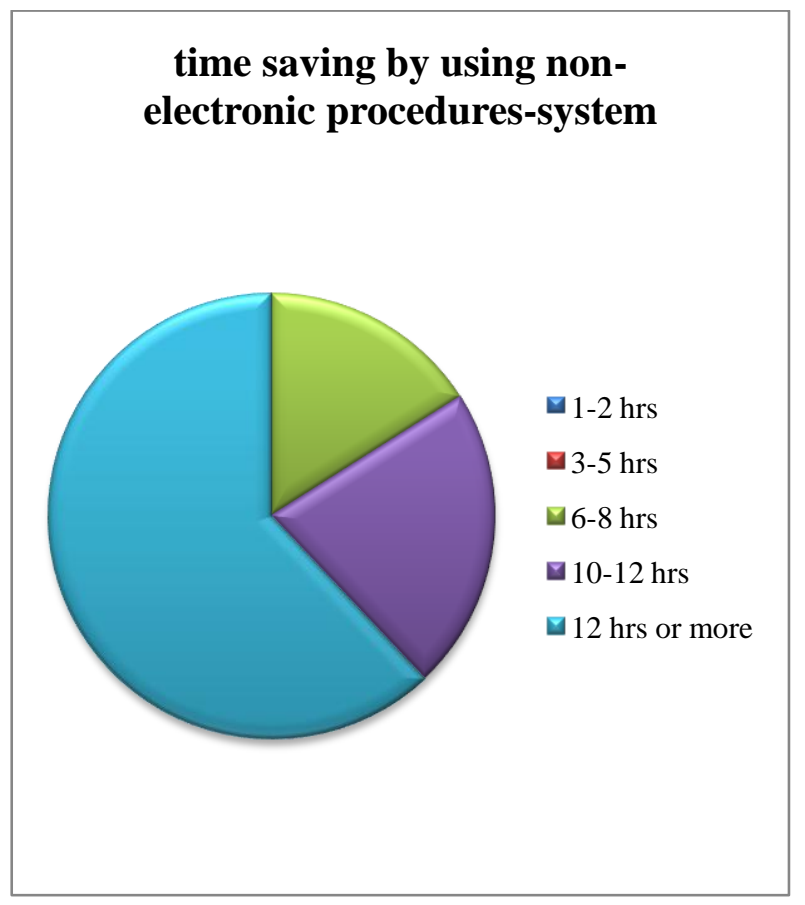

\section{saving financial cost non-electronic system}

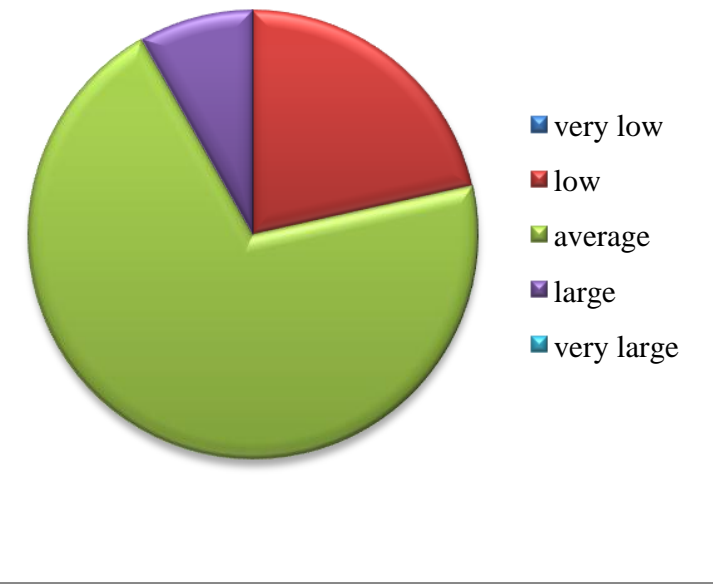

Fig.2 saving financial cost in the Non-electronic system

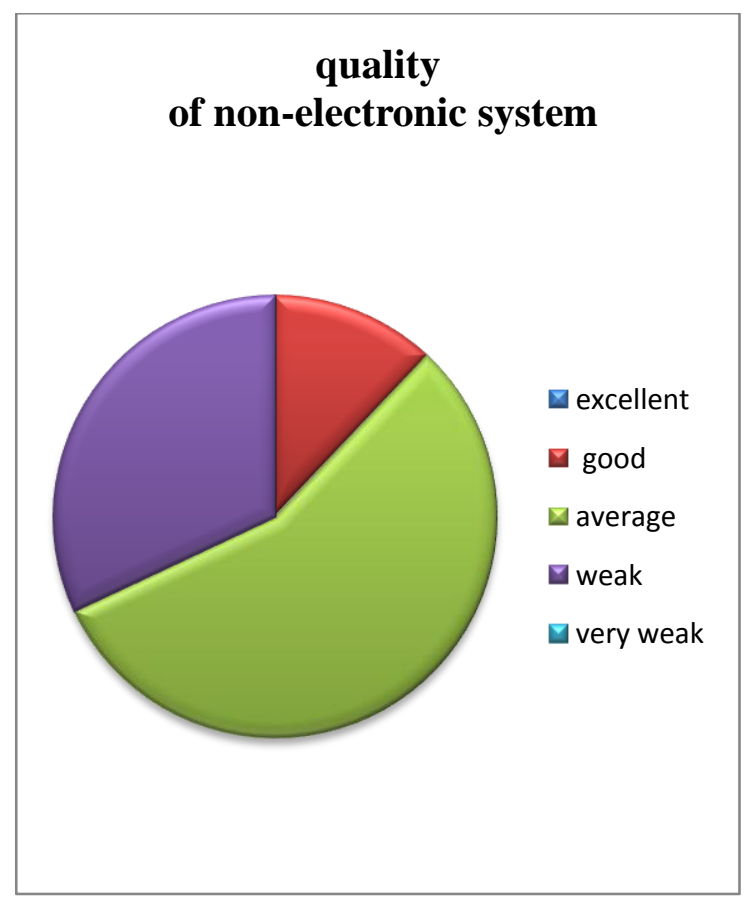

Fig.3 quality results in the Non-electronic system

Fig.1 Time-saving results in the traditional system 




Fig.4 result of use modern technologies in the Nonelectronic system

\section{2 electronic system result}

Table 2. The results of the analysis of the questionnaire -

\begin{tabular}{|c|c|c|c|c|c|c|}
\hline \multirow{2}{*}{ छે } & options & hrs 2-1 & hrs 5-3 & $\begin{array}{l}8-6 \\
\text { hrs }\end{array}$ & hrs $12-10$ & $\begin{array}{c}\text { More than } \\
12 \mathrm{hrs}\end{array}$ \\
\hline & result & $38 \%$ & $\% 62$ & $\% 0$ & $\% 0$ & $\% 0$ \\
\hline \multirow{2}{*}{$\begin{array}{l}\text { \& } \\
2\end{array}$} & options & V few & few & average & many & Too many \\
\hline & result & $\% 87.75$ & $12.25 \%$ & $\% 0$ & $\% 0$ & $\% 0$ \\
\hline \multirow{2}{*}{ 冚 } & options & excellent & good & average & weak & V weak \\
\hline & result & $\% 92$ & $\% 8$ & $\% 0$ & $\% 0$ & $\% 0$ \\
\hline \multirow{2}{*}{ 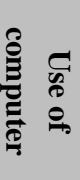 } & options & $\begin{array}{l}\text { Strongly } \\
\text { support }\end{array}$ & support & Neutral & $\begin{array}{c}\text { Not } \\
\text { supporting }\end{array}$ & $\begin{array}{l}\text { Strongly } \\
\text { not } \\
\text { supporting }\end{array}$ \\
\hline & result & $\% 100$ & $\% 0$ & $\% 0$ & $\% 0$ & $\% 0$ \\
\hline
\end{tabular}

9.2.1 Presentation of electronic system results in charts

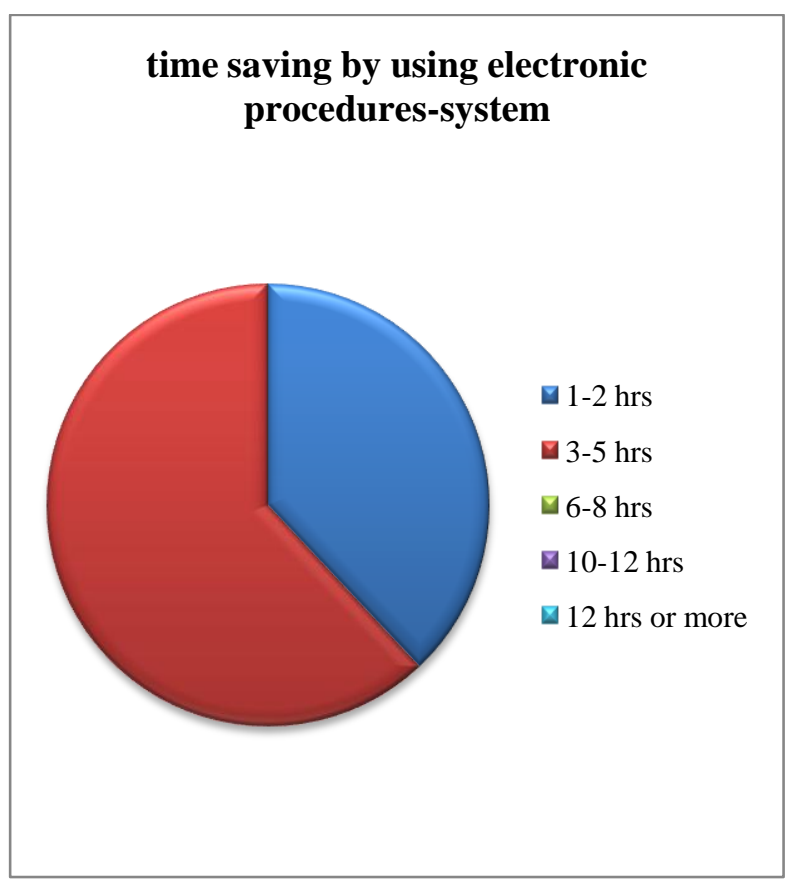

Fig.5 Time-saving results in the electronic system

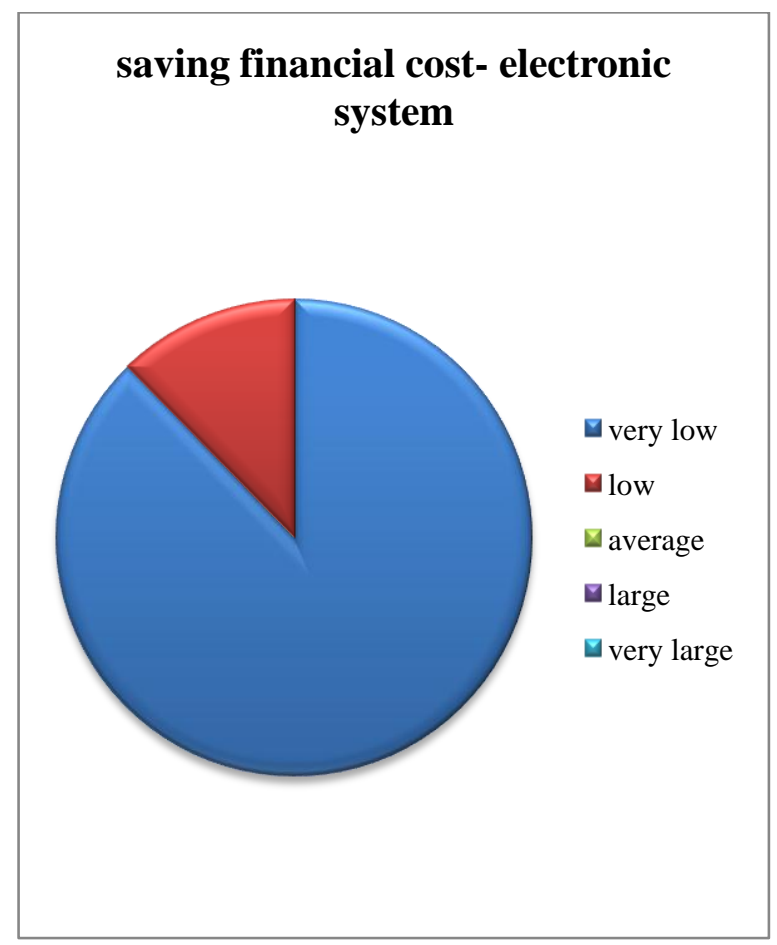

Fig.6 saving financial cost in the electronic system 


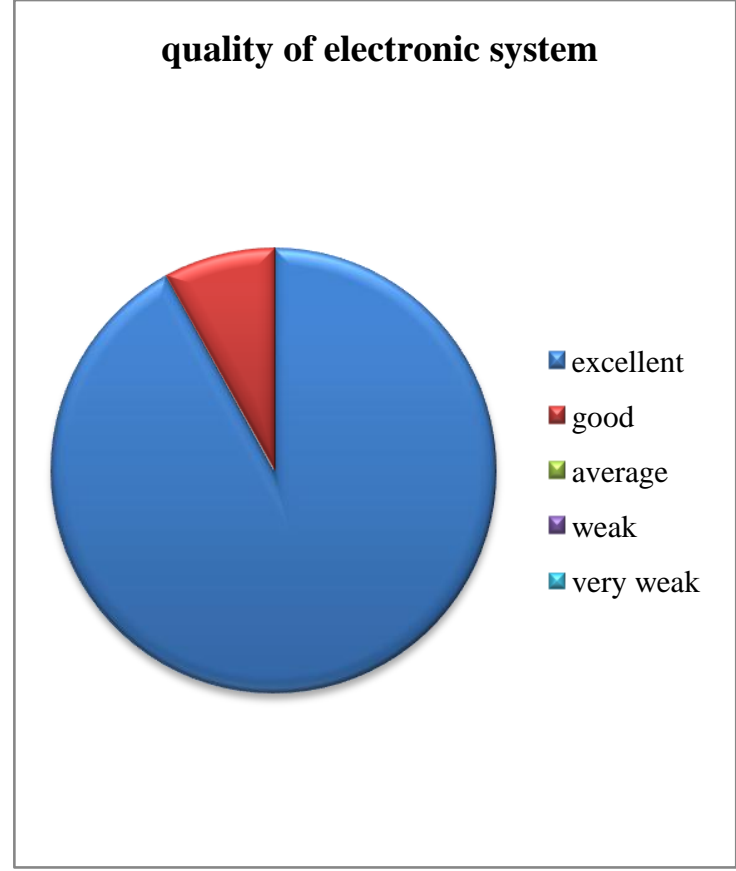

Fig.7 quality results in the electronic system

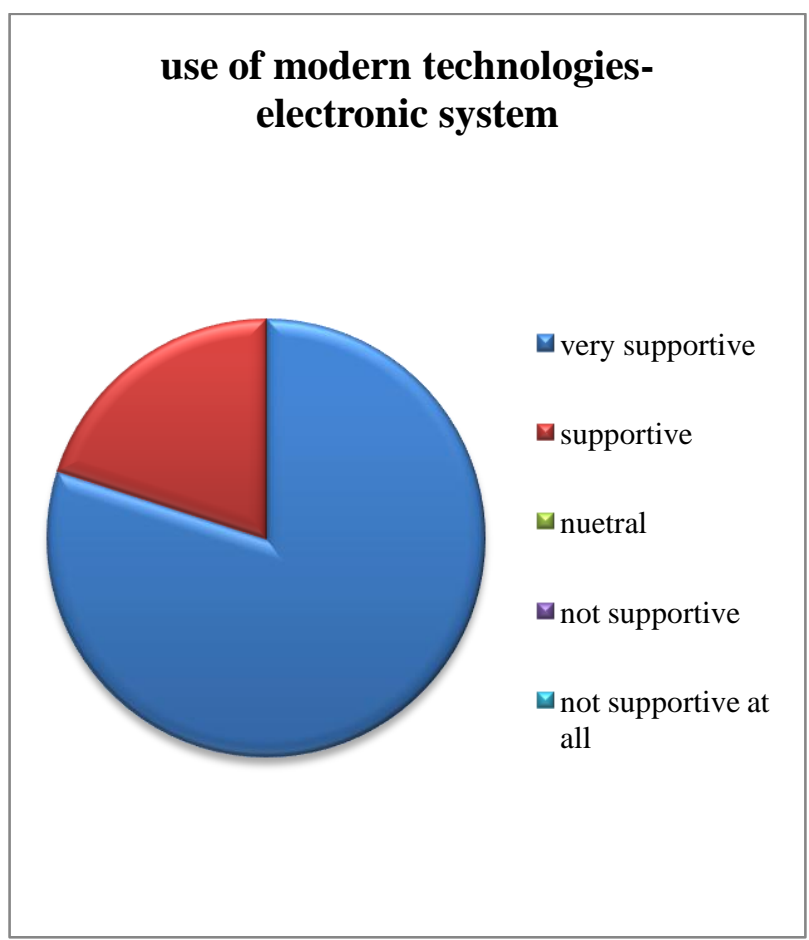

Fig.8 result of use modern technologies in the electronic system

\subsection{Summary of the questionnaire study}

After this research and inferring above conclusions although the highly effective performance would be via utilizing from available resources to achieve the goals with highly quality and lowest possible cost and keeping the rate at all the time, using the E-management system is the optimal system to achieve effective and optimal operation.

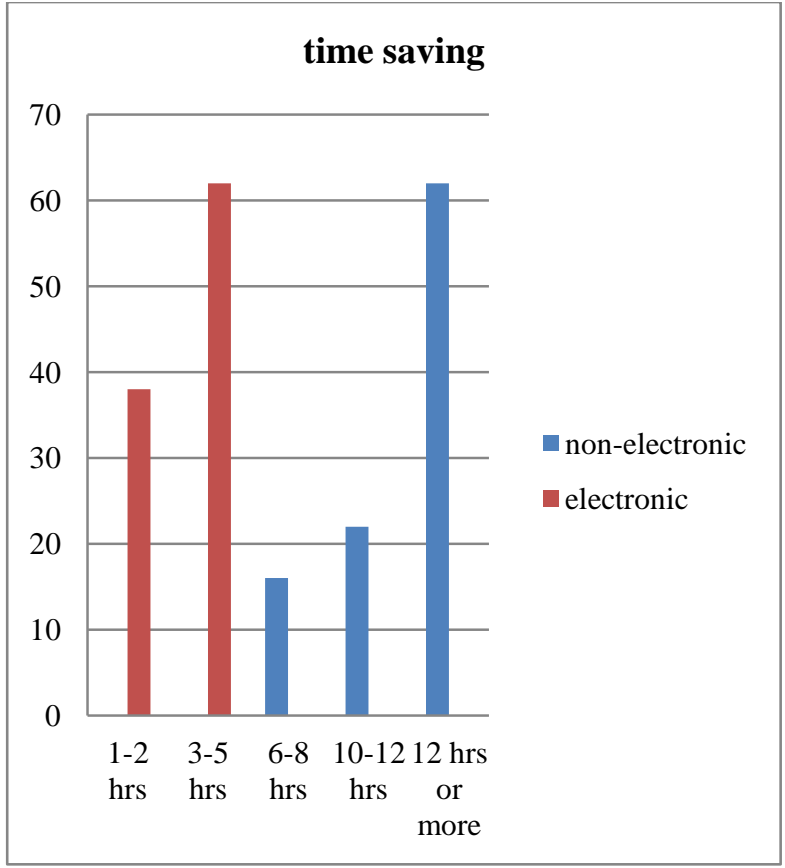

Fig.9 time saving- Comparison between electronic and non-electronic systems

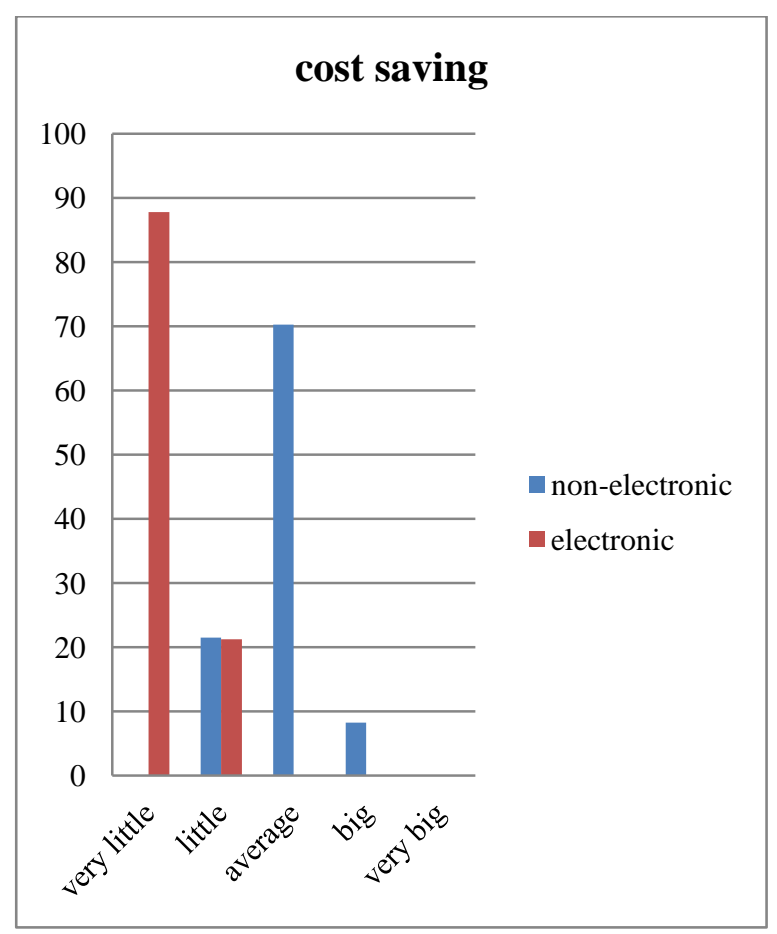

Fig.10 cost saving- Comparison between electronic and non electronic systems 


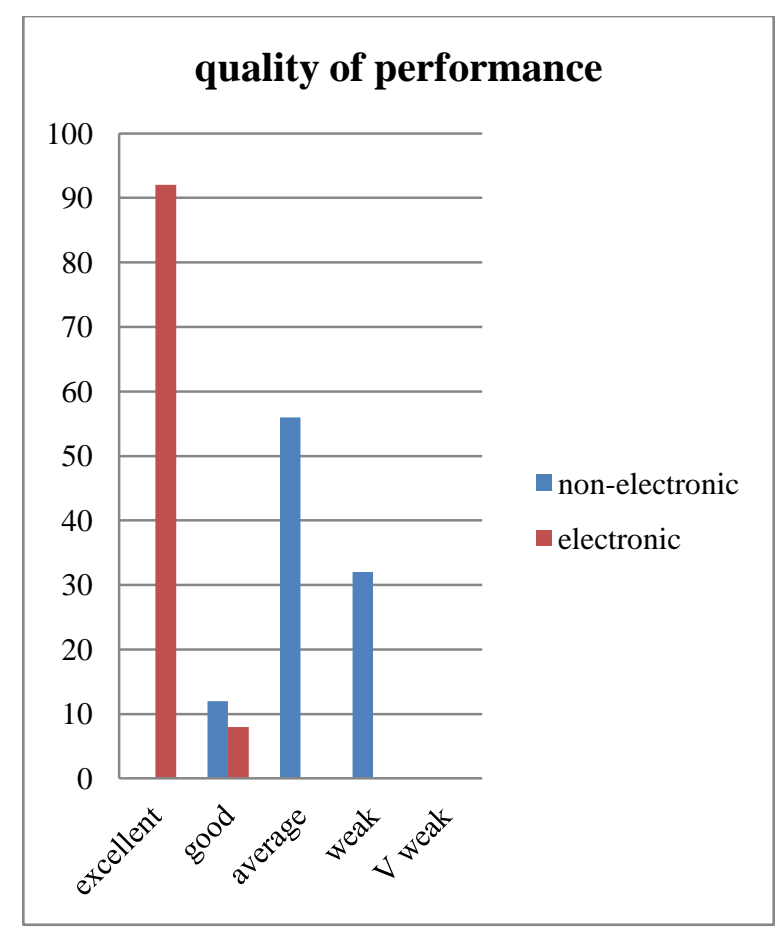

Fig.11 quality of performance - Comparison between electronic and non electronic systems

\section{CONCLUSION}

After carrying this research and applied studies the Emanagement system is the system that through applying it the effective and optimal operations would be achieved in every institutions, organizations, and projects.

The performance differ from an institution to another as well as one person to another, but the highly effective performance should maintain its uniqueness from the others over the time with less cost, while maintaining quality in service or product and timely.

I need to shade more light that the using of E-management system must be updated from time to time to keep pace with rapidly coming changes.

\section{REFERENCES}

[1] D.Sirefi Mohammed, e-governance Hotel Facilities, Dar thought University, Alexandria, 2007.

[2] D. Yassin Saad Ghalib, management, and prospects for electronic applications Arabia, King Fahd National Library, Riyadh, 2006.

[3] D. Kurd Ali Mohammed Ibrahim, Management and Leadership, and the Nile Valley for Human Development, Cairo, 2011.

[4] D. Ahmed Maher, principles of management science and skill, University House, Alexandria, 2010.

[5] Aboud, Fahd bin Nasser, the practical application of egovernment e-Government, Obeikan library, Riyadh, 2008 .

[6] Abu Mgayd, Yahya bin Muhammad, the e-government revolution on the traditional administrative work, Riyadh, 2004.

[7] Abu Samira, Mahmoud, e-government, Doha, Qatar in 2001.

[8] Medhat Ramadan, the criminal protection for ecommerce - a comparative study -, Dar Arab Alnhzh, Cairo, 2001 .

[9] Tariq Abd al-ali Hammad, e-commerce, Faculty Altharh ', Ain Shams University, 2004.

[10] Mohammed Alcerega, e-governance, Beirut, 2004. 